International Journal of Automotive and Mechanical Engineering (IJAME)

ISSN: 2229-8649 (Print); ISSN: 2180-1606 (Online); Volume 6, pp. 768-776, July-December 2012

(OUniversiti Malaysia Pahang

DOI: http://dx.doi.org/10.15282/ijame.6.2012.8.0062

\title{
INVESTIGATION OF FLOW BEHAVIOR IN MINIMUM QUANTITY LUBRICATION NOZZLE FOR END MILLING PROCESSES
}

\author{
M.S. Najiha ${ }^{1}$, M.M.Rahman ${ }^{1}$, A.R. Yusoff ${ }^{2}$ and K. Kadirgama ${ }^{1}$ \\ ${ }^{1}$ Faculty of Mechanical Engineering \\ Universiti Malaysia Pahang, 26600 Pekan, Pahang Daraul Makmur, MALAYSIA \\ Email: mustafizur@ump.edu.my \\ ${ }^{2}$ Faculty of Manufacturing Engineering \\ Universiti Malaysia Pahang, 26600 Pekan, Pahang Daraul Makmur, MALAYSIA
}

\begin{abstract}
Minimum quantity lubrication (MQL) is a sustainable manufacturing technique that has replaced conventional flooded lubrication methods and dry machining. In the MQL technique, the lubricant is sprayed onto the friction surfaces through nozzles through small pneumatically-operated pumps. This paper presents an investigation into the flow behavior of the lubricant and air mixture under certain pressures at the tip of a nozzle specially designed for MQL. The nozzle used is an MQL stainless steel nozzle, $6.35 \mathrm{~mm}$ in diameter. Computational fluid dynamics is used to determine the flow pattern at the tip of the nozzle where the lubricant and compressed air are mixed to form a mist. The lubricant volume flow is approximately $0.08 \mathrm{ml} /$ cycle of the pump. A transient, pressure-based, threedimensional analysis is performed with a viscous, realizable $\mathrm{k}-\varepsilon$ model. The results are obtained in the form of vector plots and flow fields. The flow mixing at the tip of the nozzle is wholly shown through the flow fields and vector plots. This study provides an insight into the flow distribution at the tip of the nozzle for a certain pressure to aid modifications in the design of the nozzle for future MQL studies. It attainable aids to determine the correct pressure for the air jet at the nozzle tip.
\end{abstract}

Keywords: MQL; computational fluid dynamics; transient; vector plots; contour plots.

\section{INTRODUCTION}

Minimum quantity lubrication (MQL) is an innovative machining technique alternative to conventional flooded cooling/lubrication as well as the ideal dry lubrication technique (Sapian et al., 2010). Adapting MQL as a substitute to conventional metal working fluids means addressing the concerns related to metal working fluid applications (Thakur et al., 2009). These issues are related to the economic, ecological and occupational costs of exposure to these metal working fluids. The costs associated with the use of conventional metal working fluids amount to about 7 to $17 \%$ of the total machining cost (Weinert et al, 2004) in comparison to the tool cost that ranges from 2 to $4 \%$ of the total machining cost (Rahman et al., 2012). The MQL method is part of the global sustainable manufacturing concept (Nageswara et al., 2008). Due to the rapidly increasing global interest in sustainable manufacturing, there is a surge in interest in dry machining due to the growing concern regarding the cost of purchasing cutting fluids along with its management (Skerlos et al., 2008). However, the most common 
restrictions to the use of dry machining are the costly tools and non-retrofitting equipment (Bounekri and Shaikh, 2012). Most of the studies and investigations so far carried out on dry machining are mainly related to the special tools and coatings used to assist in the dry conditions (Kobayashi et al., 2005; Klocke and Eisenblatter, 1997; Machado and Wallbank, 1997; Nouri et al., 2003; Reddy and Rao, 2006; Shen, 1996; Su et al, 2006). While dry machining can be an ideal substitute to conventional flooded machining, manufacturers are still concerned about lubrication, tool life, product deformation due to thermal effects, etc. (Davim et al., 2007; Itoigawa et al., 2006; Sun et al., 2006). In these circumstances, MQL serves as a better alternate. The application of the MQL technique in machining leads to a significant reduction in machining costs (Weinert et al., 2004). MQL can be defined as one of the techniques of sustainable manufacturing that has proven to be safe for the environment, results in less occupational exposure to the economic (Park et al., 2009). The use of a minimized quantity of metal working fluids is a direct indicator of sustainable manufacturing (Rahman et al., 2012). In the present study, a three-dimensional transient flow phenomenon is investigated through a commercial nozzle specially designed for MQL flow. The analysis of the spray nozzle flow is studied at the tip of the nozzle, where compressed air mixes with droplets of the commercial cutting lubricant designed for MQL thus forming a mist.

\section{METHODS AND MATERIALS}

The pressurized air carries the mist to the desired location. The pressure of the air at the tip of nozzle necessary to transport the mist, where air-lubricant mixing takes place, needs to be investigated. The air-lubricant mixture is carried to the friction zones via nozzles that are supplied with lubricant via small pneumatically-operated pumps. The lubricant is pushed through a capillary tube within another tube, through which the pressurized air is supplied, and mist is carried to the tool-workpiece interface where this mixture is sprayed in the form of mist. The present study is conducted to investigate the flow behavior of the lubricant and air mixture at the tip of a nozzle that is specially designed for MQL. The nozzle used is an MQL stainless steel coaxial nozzle, $6.35 \mathrm{~mm}$ in diameter, with a polyurethane tubing $3.175 \mathrm{~mm}$ outer diameter. Computational fluid dynamics is used to determine the flow pattern. A standard MQL nozzle is modeled for the study. The lubricating medium is taken as a mixture of compressed air and lubricant. The properties of the mixture are shown in Table 1.

Table 1. Mixture Properties

\begin{tabular}{ll}
\hline Description & Value \\
\hline Compressed air pressure $(\mathrm{MPa})$ & 0.1378 \\
Air viscosity $(\mathrm{kg} / \mathrm{m}-\mathrm{s})$ & $1.7894 \times 10^{-5}$ \\
Air density $\left(\mathrm{kg} / \mathrm{m}^{3}\right)$ & 1.225 \\
Lubricant viscosity $(\mathrm{kg} / \mathrm{m}-\mathrm{s})$ & 0.01 \\
Density of lubricant $\left(\mathrm{kg} / \mathrm{m}^{3}\right)$ & 890 \\
Lubricant volume flow rate $(\mathrm{kg} / \mathrm{s})$ & 0.0004 \\
\hline
\end{tabular}

The ANSYS-FLUENT solver is used for the computational study. The mixture of compressed air and lubricant are modeled as a multiphase volume of fluid, in a viscous, standard $k-\varepsilon$ model. This model is the most suitable for fully turbulent flow, 
taking into account an enhanced wall treatment. Most nozzle flows are modeled with this $k-\varepsilon$ model (Reddy and Rao, 2006; Thakur, Ramamoorthy and Vijayaraghavan, 2009). Air is set as the primary phase and lubricant is defined as the secondary phase. The mass fraction of the lubricant is assumed to be constant throughout the compressed air.

\section{NOZZLE DESIGN AND MODELING}

Figure 1 shows the stainless steel nozzle with the conical spray tip used for the MQL system. The nozzle consists of a polyurethane capillary coaxial tube and stainless steel tube fitted with an external nozzle tip made of copper. The tube assembly is provided with a flow director near the tip of the assembly. The lubricant is supplied to the nozzle via small pneumatic pumps provided with a flow regulator, and is then carried to the cutting zone. Compressed air is supplied trough the stainless steel tube. Lubricant is usually mixed with a small amount of compressed air to create the air-lubricant spray at the tip of the nozzle. This spray is then dispensed to the friction interface of the tool and workpiece via the compressed air. The present study is conducted to investigate the flow behavior of the lubricant and air mixture at the tip of a nozzle. Computational fluid dynamics is used to determine the flow pattern. The nozzle tubing arrangement is shown in Figure 2.

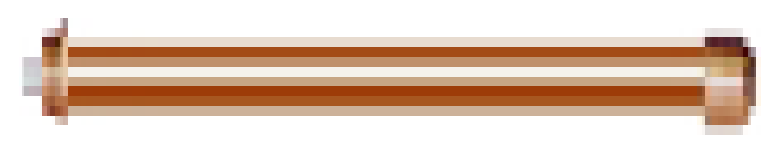

Figure 1. Stainless steel nozzle used for MQL

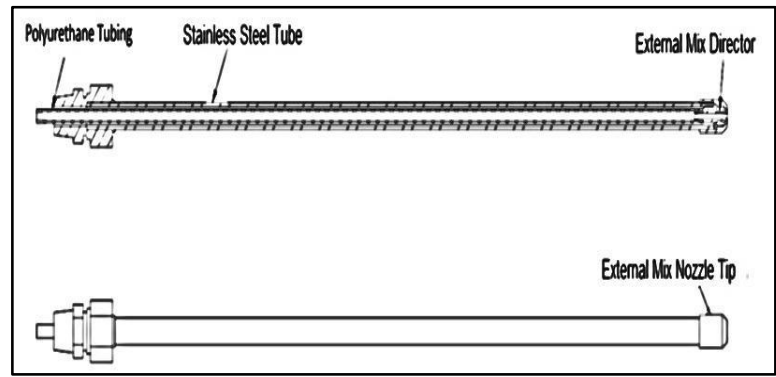

Figure 2. Schematic and sections of the nozzle

The stainless steel tube has a $6.35 \mathrm{~mm}$ outer diameter and is $305 \mathrm{~mm}$ long, while the polyurethane tube has an outer diameter of $3.175 \mathrm{~mm}$ and a length of $317.5 \mathrm{~mm}$. A three-dimensional model of the nozzle is developed using computer aided design software. The mixing of the two fluids takes place outside the nozzle. As the mixture is formed just at the nozzle tip, therefore only the nozzle tip is modeled. An enlarged view of the nozzle tip cross-section is shown in Figure 3. A three dimensional solid model of the nozzle tip is shown in Figure 4. 


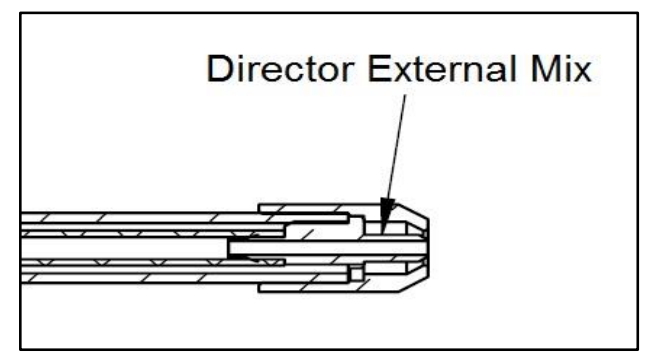

Figure 3. Cross-section of the nozzle tip.

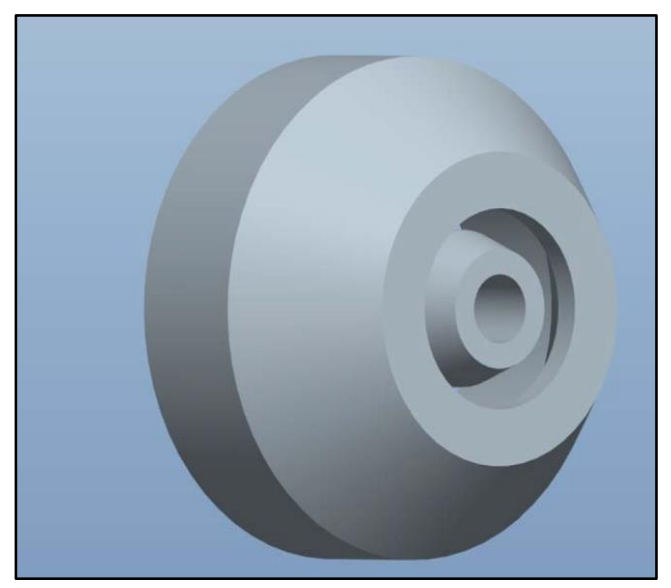

Figure 4. Three-dimensional structural model of the MQL nozzle tip.

An unstructured mesh with tetragonal elements is used with a minimum edge length of $0.055 \mathrm{~mm}$. The meshed domain is shown in Figure 5. The skewness of the tetragonal elements and the respective number of cells are presented in Figure 6. According to this graph, the maximum skewness is below 0.3 , with $1.6 \%$ of the total number of elements. Thus it shows that the mesh quality is appropriate for the simulation. The nozzle is modeled for a balanced mass flow rate within the domain. Smaller mesh sizes are selected to determine the convergence in the lubricant flow section.

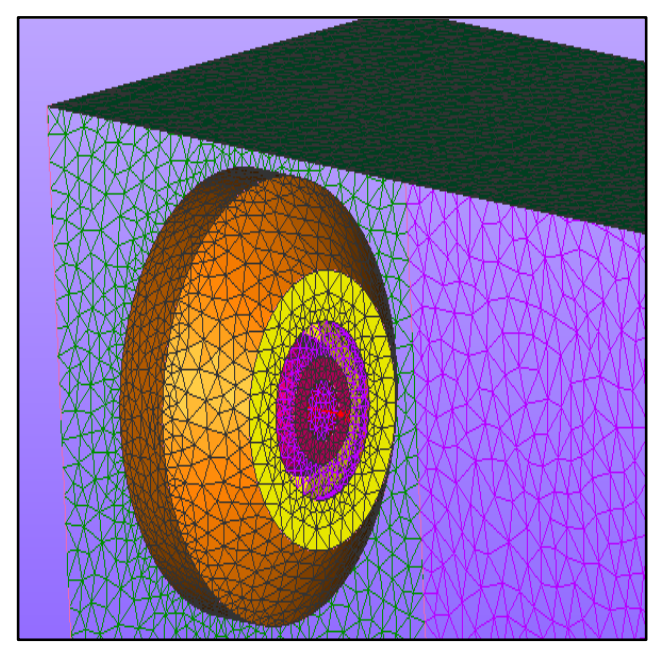

Figure 5. Mesh domain of the nozzle. 


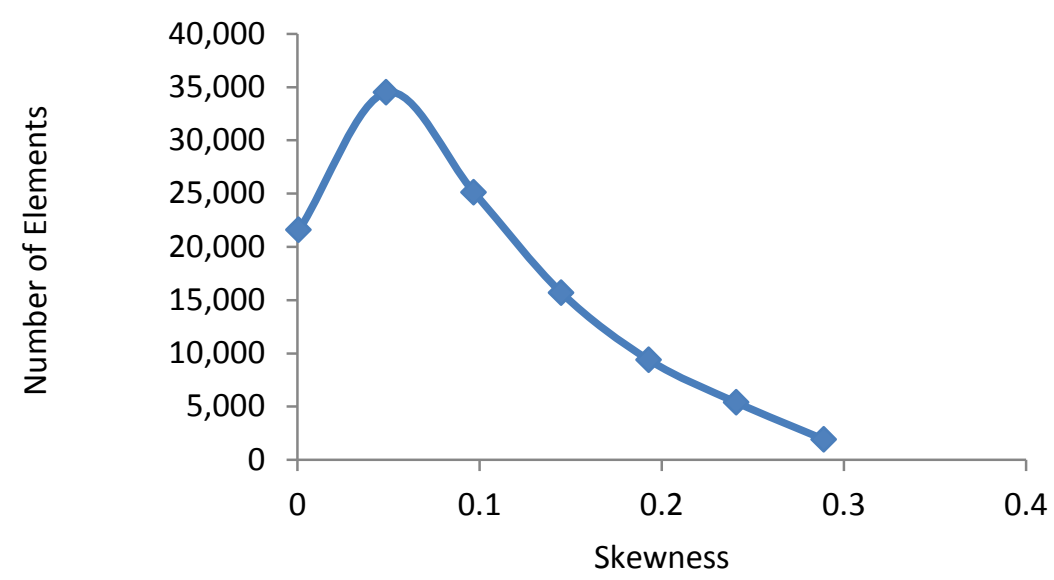

Figure 6. Skewness of tetragonal elements versus the number of elements.

\section{RESULTS AND DISCUSSION}

The flow behavior of the compressed air and lubricant is studied. The flow is modeled using the ANSYS-FLUENT solver without air. Figure 7 shows the velocity vectors and contours of the volume fraction for the lubricant without any compressed air supply. It can be seen that the maximum velocity of the lubricant is $0.757 \mathrm{~m} / \mathrm{s}$, which is very small for carrying the lubricant to the cutting zone. Oil condenses just after exiting the nozzle tip in the form of droplets. Hence the compressed air is used as the spraying medium. The position of the lubricant drops from the nozzle tip is plotted against volume fraction in Figure 8. It can be observed that the lubricant only covers a small distance of $1.5 \mathrm{~mm}$ from the tip of the nozzle. The small distance between the nozzle tip and the toolworkpiece interface results in an interaction with chips. Therefore, in order to produce an aerosol spray that carries the lubricant to the tool-work-piece interface, compressed air is supplied to the nozzle.

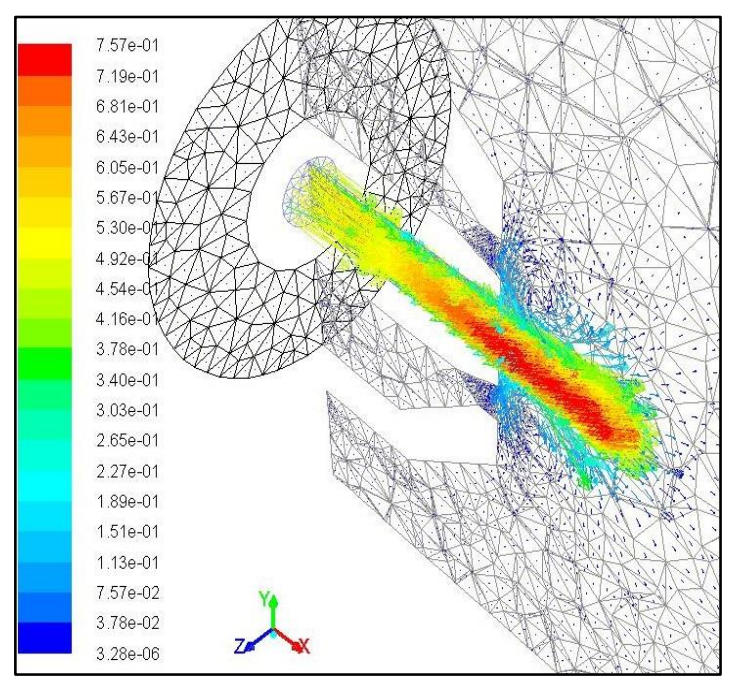

(a) Velocity vector

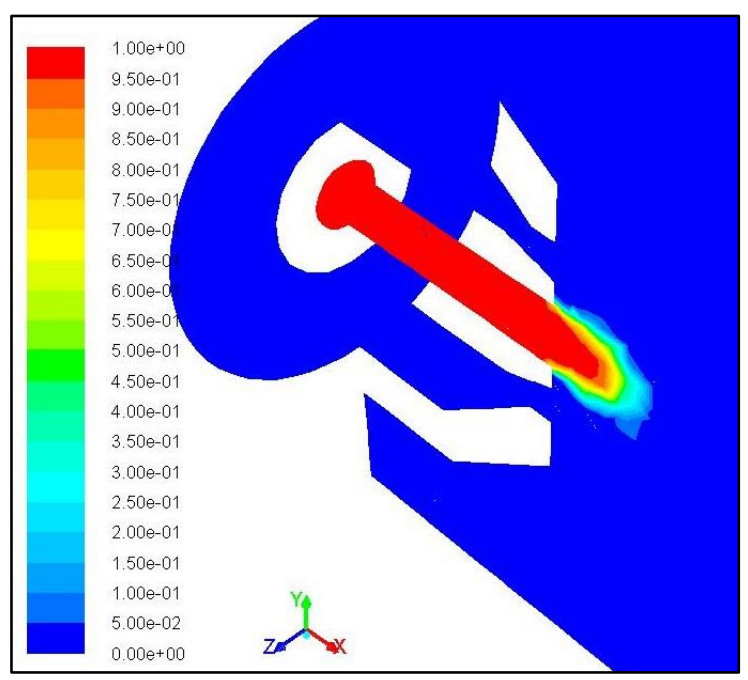

(b) Contours of volume fraction

Figure 7. Velocity vector and volume fraction contour for flow of lubricant drops. 
The compressed air flow is simulated with the lubricant drops outside of nozzle. The velocity vectors and contour plots for the mixture flow are shown in Figure 9. The velocity vector creates eddies in the nozzle when compressed air exits. The lubricant is dispersed with compressed air and becomes mist. After a certain distance, the lubricant is completely mixed with the compressed air forming a spray, therefore only one phase (air) exists. The required spray strength depends on the pressure of the air. Figure 9 shows that the average velocity of the air-lubricant mixture is $600 \mathrm{~m} / \mathrm{s}$, which is large enough to carry the lubricant to the cutting zone. Oil drops mix with the compressed air forming an aerosol spray.

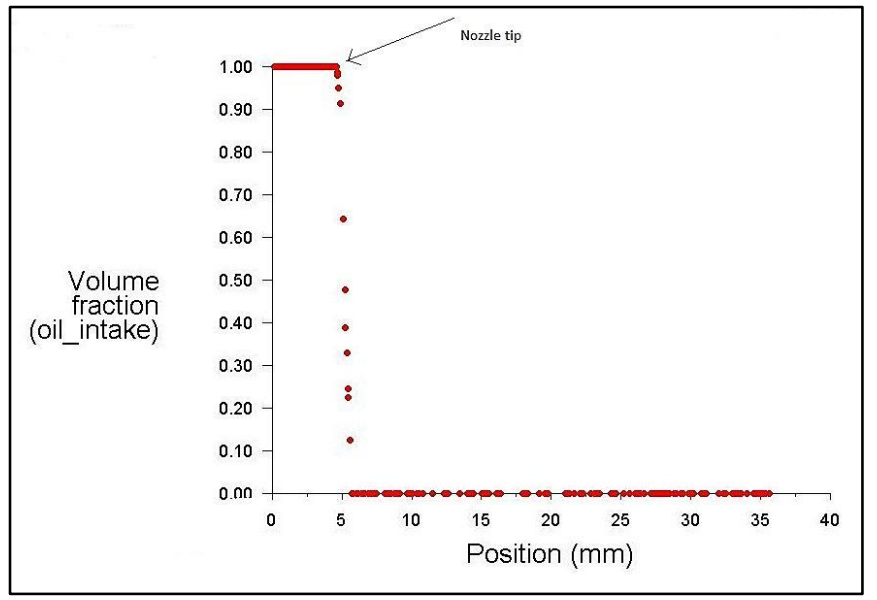

Figure 8. Position of lubricant drops from the nozzle tip.

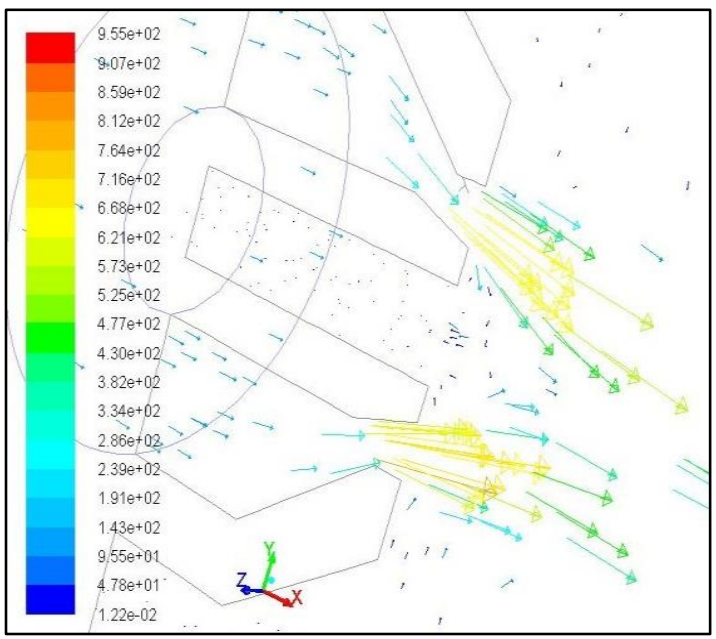

(a) Velocity vectors

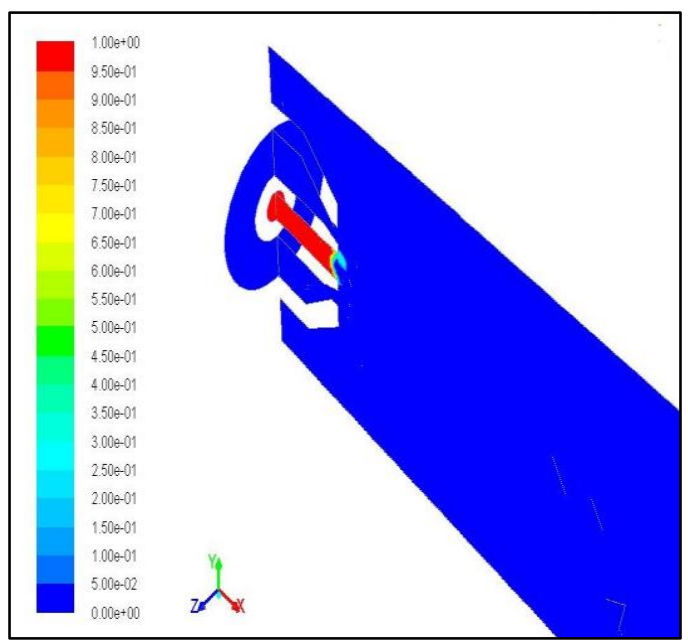

(b) Contours of volume fraction

Figure 9. Velocity vector and volume fraction contour for compressed air-lubricant mixture.

Path lines for the flow of the lubricant drops are shown in Figure 10. These path lines clearly show that the lubricant drops travel some distance before the mist is formed. When air is supplied to the nozzle, the distance travelled by the lubricant is increased to approximately 5-6 mm (Figure 11), after which the lubricant fraction in the aerosol becomes negligible. This distance is important with respect to the effective 
dispersion of the spray. The rise in volume fraction at $12.5 \mathrm{~mm}$ is mainly due to the formation of eddies in the simulation, resulting in the oil volume fraction increasing at that location. This is not a point of concern as the nozzle distance in the machining setup is no more than 5-6 mm, and consequently this phenomenon will not cause any problems.

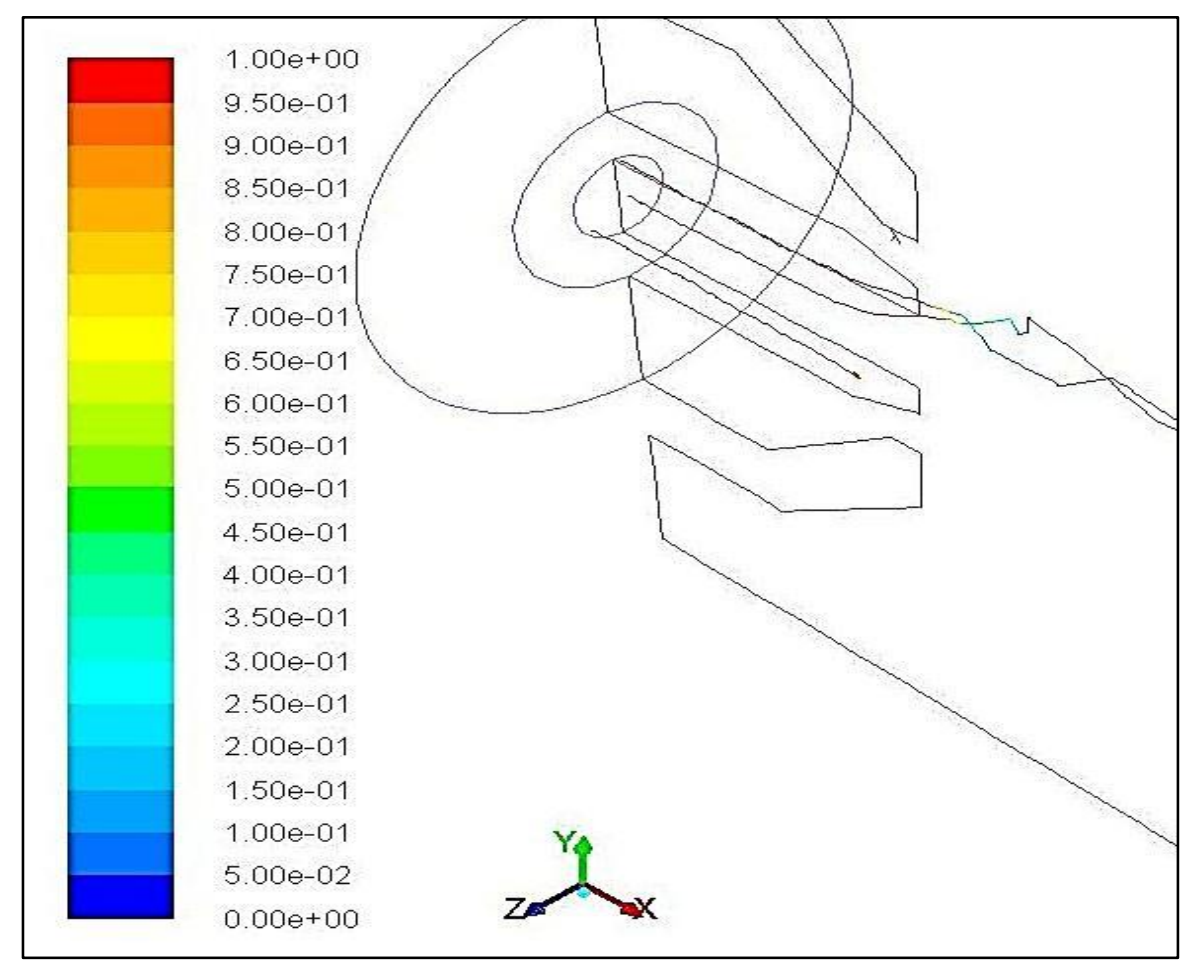

Figure 10. Path lines of compressed air-lubricant mixture.

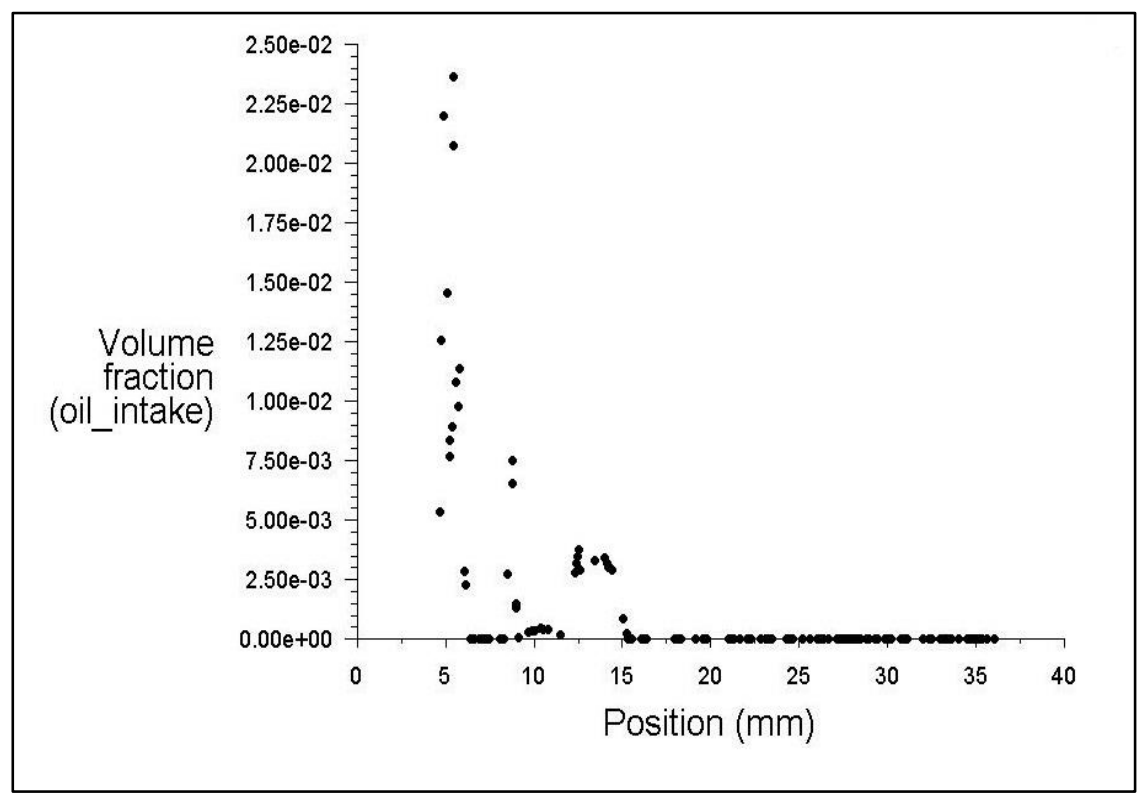

Figure 11. Position of the transported lubricant drops. 


\section{CONCLUSION}

A 3-dimensional study with a commercially available MQL nozzle is carried out in order to determine the flow pattern of an aerosol mixture formed with a combination of lubricant droplets and compressed air. The pressure of the air plays a vital role in forming a uniform mist with the lubricant. In this case, the air pressure is sufficient to transport the lubricant droplets a certain distance in the form of a mist. The formation of the mixture at the tip of the nozzle is shown through flow fields and vector plots. This study provides an insight into the flow distribution at the tip of the nozzle for a certain pressure to help carry out modifications on the design of the nozzle for future studies in MQL, as well as determine a more efficient operating pressure for the air jet. Further research with different operating pressures and mesh sizes may be conducted in order to establish the range of required operating pressures.

\section{REFERENCES}

Boubekri, N. and Shaikh, V. 2012. Machining using minimum quantity lubrication: a technology for sustainability. International Journal of Applied Science and Technology, 2(1): 111-115

Davim, J.P., Sreejith, P.S. and Silva, J. 2007. Turning of brasses using minimum quantity of lubricant and flooded lubricant conditions. Materials and Manufacturing Processes, 22: 45-50.

Itoigawa, F., Childs, T.H.C., Nakamura, T. and Belluco, W. 2006. Effects and mechanisms in minimal quantity lubrication machining of aluminum alloy. Wear, 260(3): 339-344.

Klocke, F. and Eisenblatter, G. 1997. Dry cutting. Annals of the CIRP, 46: 519-526.

Kobayashi, S., Ohgoe, Y., Ozeki, K., Sato, K., Sumiya, T., Hirakuri, K.K. and Aoki, H. 2005. Diamond-like carbon coatings on orthodontic archwire. Diamond and Related Materials, 14: 1094-1097.

Machado, A.R. and Wallbank, J. 1997. Effect of extremely low lubricant volumes in machining. Wear, 210: 76-82.

Nageswara, R., Damera, I. and Vamsi, K.P. 2008. Performance profiling of boric acid as lubricant in machining. Journal of the Brazilian Society of Mechanical Sciences and Engineering, 30(3): 239-244.

Nouari, M., List, G., Girot, F. and Coupard, D. 2003. Experimental analysis and optimisation of tool wear in dry machining of aluminium alloys. Wear, 255: 1359-1368.

Park, D., Stewart, P.A. and Coble, J.B. 2009. Determinants of exposure to metalworking fluid aerosols: a literature review and analysis of reported measurements. The Annals of Occupational Hygiene, 53(3): 271-288.

Rahman, M.M., Najiha, M.S. and Yusoff, A.R. 2012. Minimum quantity lubricant flow with single and three nozzles for four teeth milling cutter: a CFD approach. Advanced Science Letters (in press).

Reddy, N.S.K. and Rao, P.V. 2006. Selection of an optimal parametric combination for achieving better surface finish in dry milling using genetic algorithms. International Journal of Advanced Manufacturing Technology, 28: 463-473.

Sapian, N.F., Omar, B. and Shukor, M.H.A. 2010. Integrated mechanical pulse jet coolant delivery system performance for minimal quantity lubrication. International Journal of Integrated Engineering (Issue on Mechanical, Materials and Manufacturing Engineering), 2(1): 53-68. 
Shen, C.H. 1996. The importance of diamond coated tools for agile manufacturing and dry machining. Surface and Coating Technology, 86-87: 672-677.

Skerlos, S.J., Hayes, K.F., Clarens, A.F. and Zhao, F. 2008. Current advances in sustainable metalworking fluids research. International Journal of Sustainable Manufacturing, 1(1/2): 180-202.

Su, Y.L., Liu, T.H., Su, C.T., Yao, S.H., Kao, W.H. and Cheng, K.W. 2006. Wear of CrC-coated carbide tools in dry machining. Journal of Materials Processing Technology, 171: 108-117.

Sun, J., Wong, Y.S., Rahman, M., Wang, Z.G., Neo, K.S., Tan, C.H. and Onozuka, H. 2006. Effects of coolant supply methods and cutting conditions on tool life in end milling titanium alloy. Machining Science and Technology, 10: 355-370.

Thakur, D.G., Ramamoorthy, B. and Vijayaraghavan, L. 2009. Optimization of minimum quantity lubrication parameters in high speed turning of superalloy Inconel 718 for sustainable development. World Academy of Science, Engineering and Technology, 54: 226-228.

Weinert, K., Inasaki, I., Sutherland, J. W. and Wakabayashi, T. 2004. Dry machining and minimum quantity lubrication. CIRP Annals - Manufacturing Technology, 53(2): 511-537. 